\title{
Intracranial Dysgerminomas
}

\author{
G. LEBLANC ${ }^{* *}$, J. FRANCOEUR**, M. COPTY**, C. CONTRERAS ${ }^{* * *}$ and F. GAGNE****
}

SUMMARY: We have reported three cases of intracranial dysgerminoma. The origin of these tumors has been controversial for a long time. It is now accepted that they develop from germ cells. The diagnosis is often difficult to confirm because of the variety of signs. If their origin is now accepted, the best way to deal with these lesions is still comtroversial. They can be macroscopically removed if they are in the pineal region. Such treatment is not possible for suprasellar tumors. Since these tumors can motastasize, radiation should be administered as soon as a pathological diagnosis is obtained. It is our belief that it should be administered to the whole spinal axis.

RÉSUMÉ: Nous avons voulu vous présenter trois (3) cas de dysgerminome intra-crânien, tumeur rare et dont l'origine a été pendant longtemps controversée. Il est reconnu actuellement cependant que le dysgerminome prend son origine de cellules germinales.

Le traitement de ces lésions, lorsque diagnostiquées, demeure un sujet de controverse mais les techniques neurochirurgicales actuelles nous permettront sans doute de pouvoir attaquer plus facilement ces lésions lorsqu'elles se développent dans la région pinéale que dans la région suprasellaire. Puisque ces tumeurs sont potentiellement métastatiques, il faut avoir recours à la radiothérapie avec irradiation de tout l'axe cérébrospinal.

This paper was presented at the Canadian Congress of Neurological Sciences meeting in June 1975. London, Ontario.

**From the neurosurgical service at l'Enfant-Jésus Hospital, Quebec City.

***Resident, neurosurgical service, l'Enfant-Jésus Hospital, Quebec City.

****Neuropathologist, l'Enfant-Jésus Hospital, Quebec City

Reprint requests to Dr. Jacques Francoeur at J'Enfant-Jésus Hospital, 1401, 18 ième Rue, Quebec, Canada Gis 1 Z4.
Intracranial dysgerminomas are rare and their clinical characteristics are difficult to establish with certainty. These include diabetes insipidus, hypopituitarism, visual disturbances, with or without signs of increased intracranial pressure. We would like to report three cases which were encountered in a thirty month period on the neurosurgical service at l'Enfant-Jésus Hospital in Quebec City.

\section{First Case:}

Our first patient (S.L.) was a sixteen year old girl: for three years she had polyuria and polydipsia but refused to be investigated. Her admission was precipitated by the onset of moderate to severe pulsating headache early in the morning, lasting thirty to forty-five minutes, of four weeks duration. She complained also of intermittent diplopia. The general physical examination revealed a small sixteen year old girl with poorly developed secondary sexual characteristics.

Neurological examination revealed a right sixth nerve palsy. The presence of diabetes insipidus was confirmed by neuroendocrinological investigation. An air encephalogram did not visualize the fourth ventricle and a Conray 60 ventriculogram showed hydrocephaly and a large tumor in the posterior part of the third ventricle (Fig. 1). A ventriculoperitoneal shunt was done to correct the increased intracranial pressure and the patient was subsequently submitted to radiation therapy. She was discharged with a diagnosis of tumor in the posterior part of the third ventricle, pinealoma probable.

She was well for fourteen months. She was then readmitted with a one month history of dizziness, a one week history of vomiting, headache, drowziness and diplopia.
Her neurological examination revealed drowziness, nystagmus in all directions, and bilateral papilledema.

Her shunt was not functioning properly and it was immediately revised. Since there was no improvement following revision, another Conray 60 ventriculogram was rapidly done. This showed complete disappearance of the tumor in the posterior part of the third ventricle, but a large fourth ventricle tumor was visualized (Fig. 2). A posterior fossa exploration was done and a large pinkish gray tumor was macroscopically removed from the fourth ventricle and superior vermis. From the biopsy specimen (No. 189-74) a pathological diagnosis of dysgerminoma was made. She was treated with chemotherapy, since the radiotherapist did not want to radiate her again. Three months later she was readmitted with signs of increased intracranial pressure. She died rapidly.

At autopsy (No. 96-74) the brain weighed $1370 \mathrm{~g}$, the surface was flattened and there was a thin herniation of the right temporal uncus under the tentorium. The third ventricle and both lateral ventricles were filled with soft, pink, friable tumor tissue. The cavities were distended and the septum pellucidum was destroyed as well as most of the fornix (Figs. 3 and 4). Only the occipital horns of the ventricular system were free. The tumor measured $7 \mathrm{~cm}$ in its vertical axis and $5 \mathrm{~cm}$ in width; it invaded the ventricular walls only slightly. The aqueduct of Sylvius was obliterated at its origin but the few distal millimeters were free of detectable tumor tissue. Such tissue, nevertheless, filled and distended the fourth ventricle, extending into the left cerebellar hemisphere (Fig. 4). The tissue occupying the fourth 


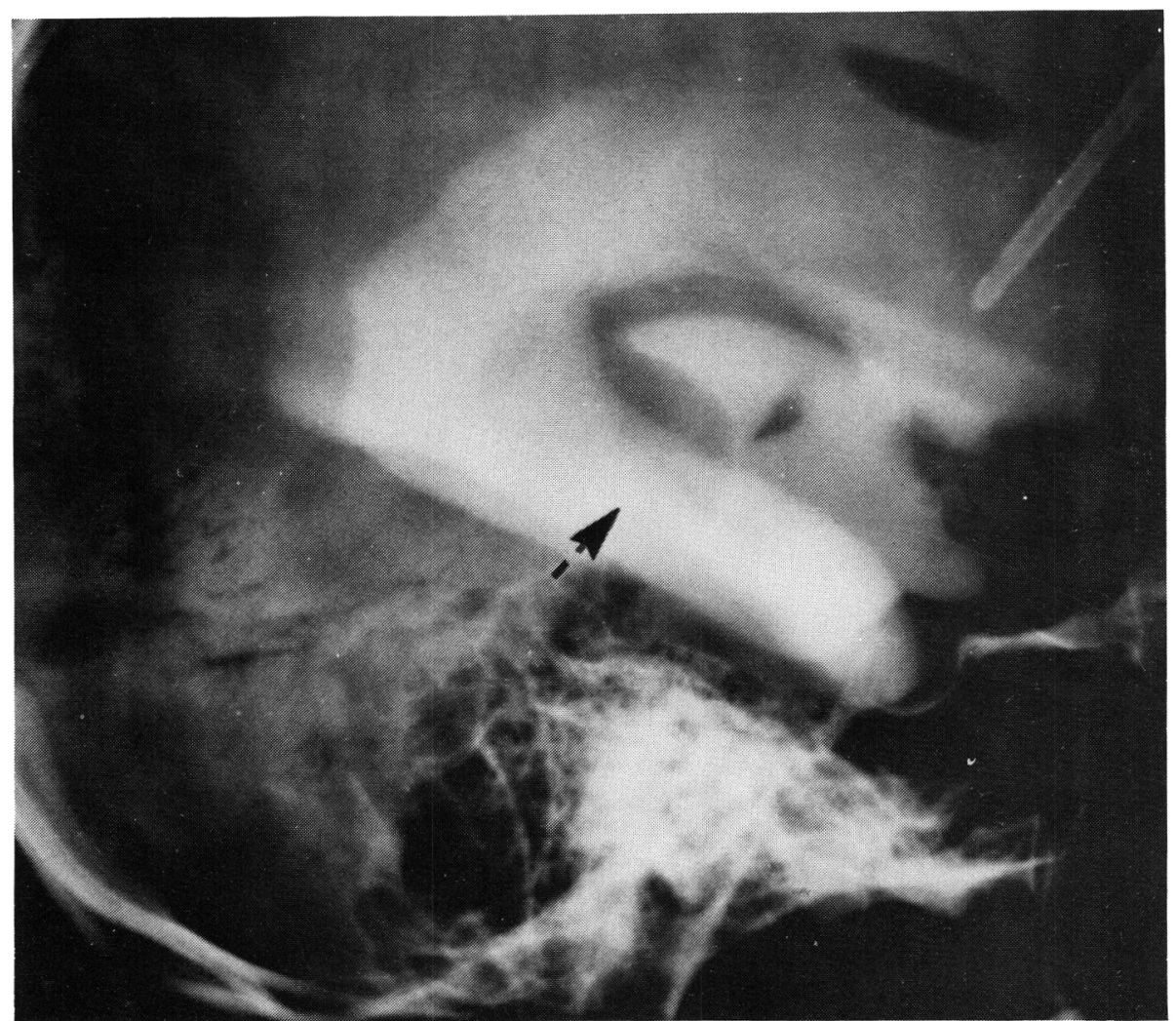

Figure 1-Case 1. A large tumor is seen in the posterior part of the third ventricle. The aqueduct was not visualized.

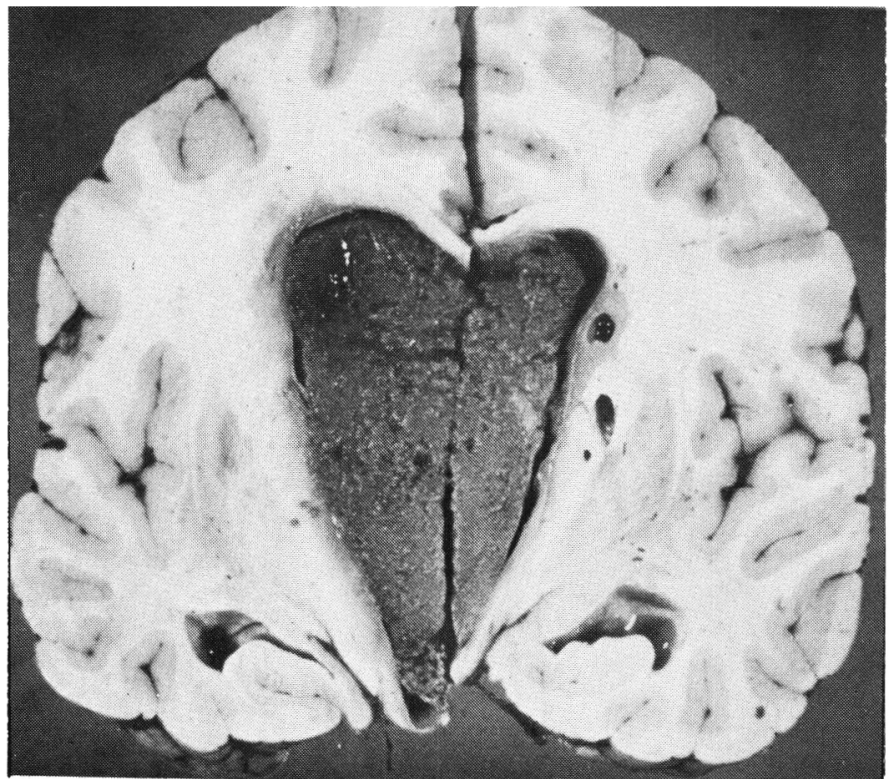

Figure 3-Case 1. Coronal section of the brain showing tumor tissue filling the ventricular system and destroying the midline structures. ventricle was darker, grayish with reddish zones.

Histologic examination of the tumor revealed wide strands or diffuse proliferation of large cells with aboundant clear cytoplasm and rather big slightly irregular nuclei. In nearly all fields and mostly close to blood vessels there were lymphocytes (Fig. 5). In some sections, all from the fourth ventricular lesion, some plasmodial formations were noted identical to those seen in trophoblastic tissue. Such elements might be considered as representing a discrete choriocarcinomatous component associated with the dysgerminal lesion. Macroscopic and histologic examination both failed to demonstrate any trace of pineal tissue. The gland was very probably destroyed with the primary tumor by the radiation therapy.

\section{Second Case:}

In November 1973, this seventeen year old boy (R.D.) was admitted to our service for investigation of a progressive decrease in visual acuity noted during the previous two months. Four months prior to his admission a diagnosis of nephrogenic diabetes insipidus had been made in another center where he had been admitted for investigation of polyuria and polydypsia of two months duration. The only abnormality found on examination was a total loss of vision in his left eye and light perception only in his right eye.

A complete neuroradiological investigation including an air en-

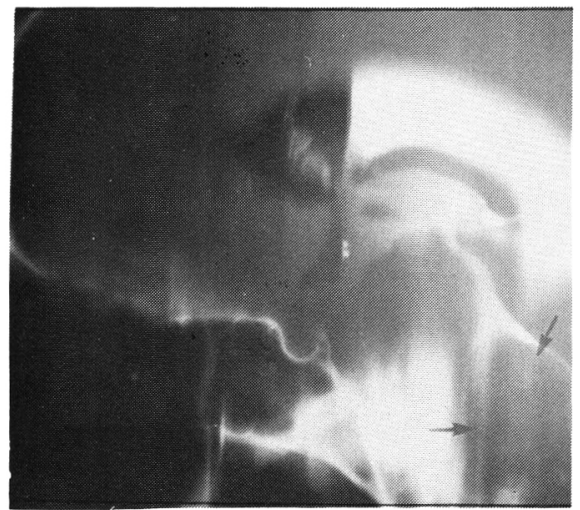

Figure 2-Case 1. The posterior third ventricle tumor has disappeared; a large tumor is present in the fourth ventricle. 
cephalogram and a Conray 60 ventriculogram was done and no definite conclusion was obtained. The patient was submitted to an exploratory craniotomy: the left optic nerve appeared slightly enlarged as well as the chiasma but no biopsy was done.

The patient left the hospital four weeks later and after a long discussion, a discharge diagnosis of demyelinating disease was proposed.

$\mathrm{He}$ was well for five months. He was then readmitted confused, having been anorexic for one week, with spasticity in his four limbs and severe electrolyte imbalance. He died within forty-eight hours.

At autopsy, (No. 109-74) the brain weighed $1540 \mathrm{~g}$ and the surface was flattened. The ventricular system contained a slightly lactescent liquid and the lumina were only slightly distended. Serial coronal sections of the brain showed tumor tissue coating the walls of the third ventricle and invading its surfaces to a thickness of about $5 \mathrm{~mm}$, practically filling the distended lumen (Fig. 6). Tumor tissue was grayish pink, soft and friable. Through the wall of the supraoptic recess it invaded the optic chiasm which was irregularly thickened, as were the adjacent segments of the optic nerves. Caudally, the lesion infiltrated the hypothalamus and the thalamus extending backward slightly more to the left side close to the quadrigemi-

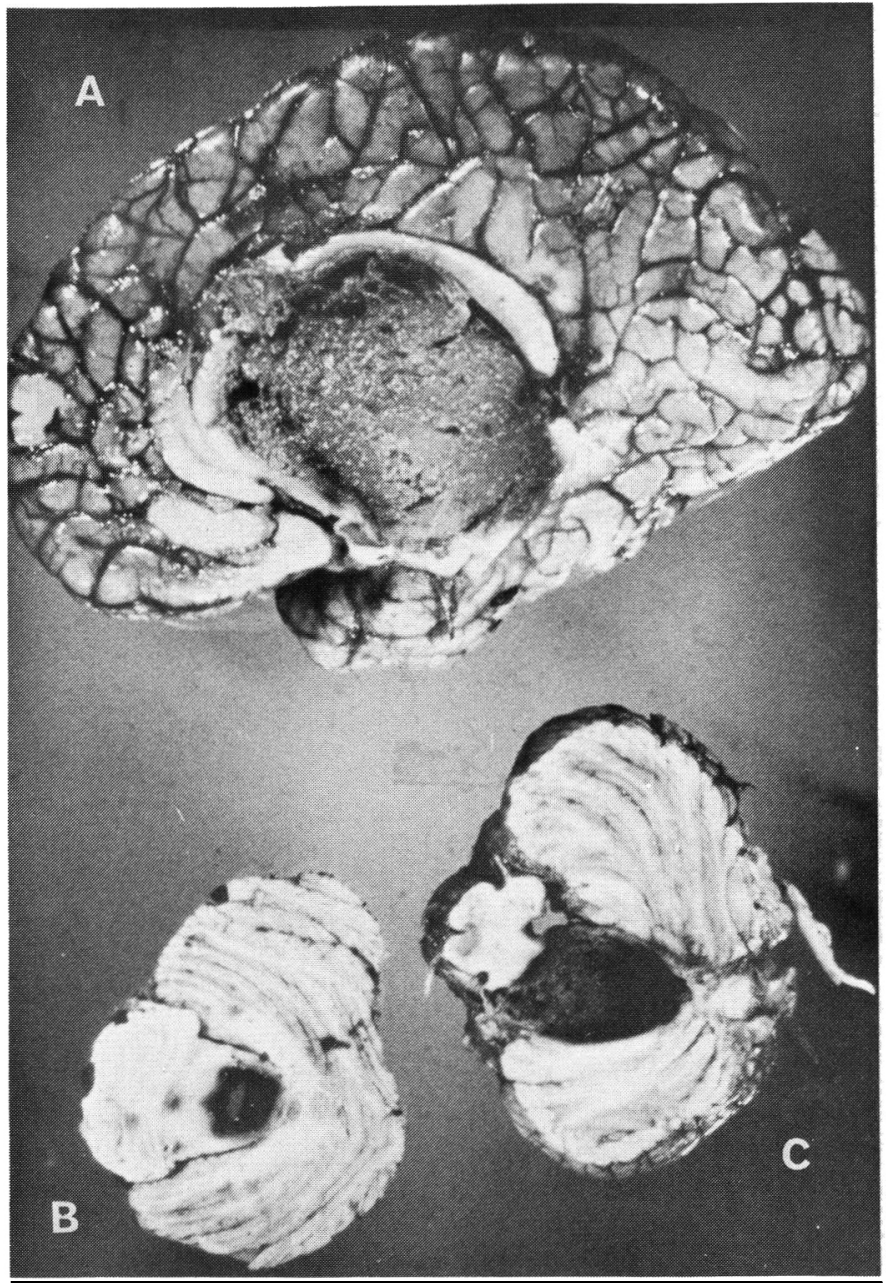

Figure 4-Case 1. A. - Midline aspect of the right cerebral hemisphere showing the third ventricle distended by tumor. The pineal gland is absent. Corpus callosum and quadrigeminal region are discretely invaded.

B. \& C. Horizontal sections showing the fourth ventricle distended by dark tumor tissue compressing and slightly invading the left cerebellar hemisphere.

nal bodies and the pineal stalk. In sections taken from that area tumor tissue could be identified partly invading an otherwise well preserved densely calcified gland. With this partial pineal involvement, and the marked proliferation in the rostral parts of the brain, and with the first symptoms referable to the anterior areas, it can reasonably be assumed that the present tumor took its

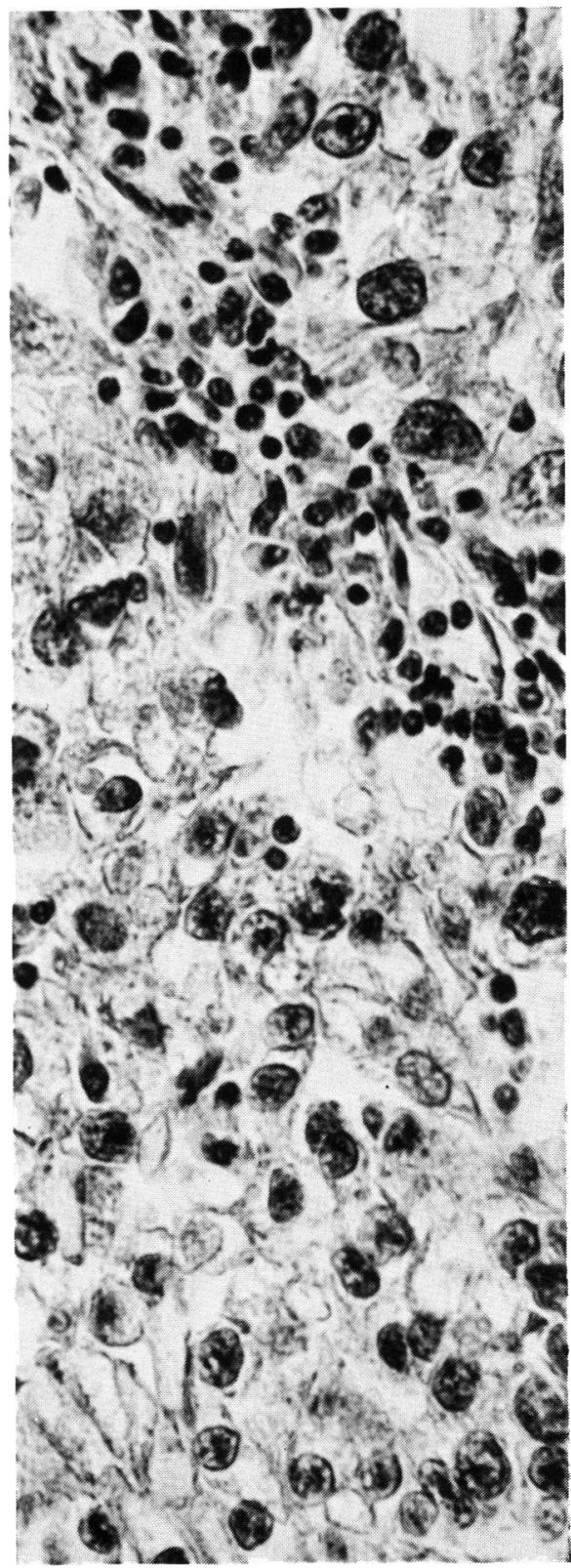

Figure 5-Case 1. The tumor is made of diffuse fields of large cells with clear cytoplasm and rather big moderately irregular nuclei. Lymphocytes can be seen, mostly close to blood vessels. (Hematoxylin-phloxin-saffron $X$ 1000). 

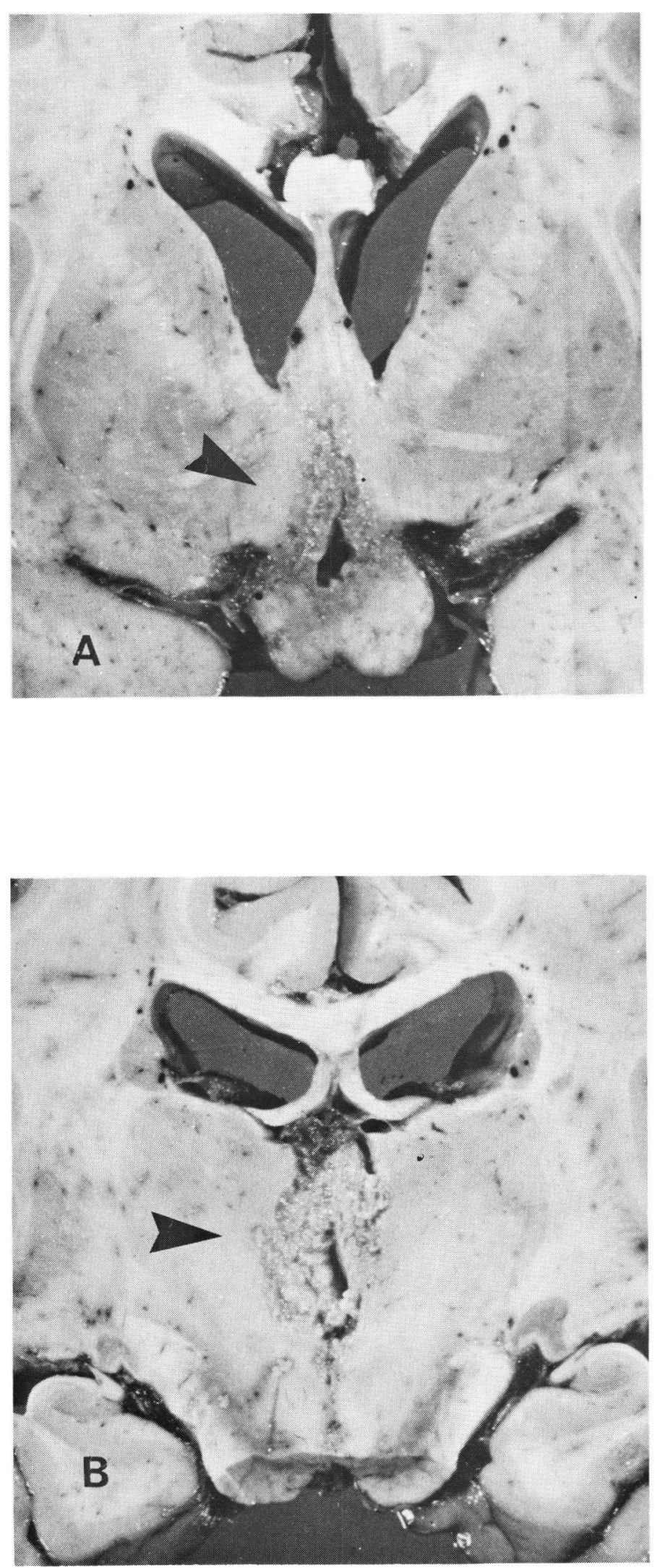

Figure 6-Case 2. Two coronal sections of the midline structures of the brain, one (A) showing the neoplastic infiltration of the third ventricular wall and also of the optic chiasm. The other section (B) shows the lesion at the thalamic level. origin from the hypothalamochiasmatic region.

Histologically the appearance was basically identical to that described in case 1 , with the differences that the cellular cytoplasm was not so clear and there were no multinucleated elements. Th lymphocytic component was present.

\section{Third Case:}

A nine year old boy (A.E.) was admitted to our service for investigation of morning headache, vomiting and diplopia of four weeks duration.

He had bilateral papilledema with hemorrhage, a bilateral internal rectus palsy, trunkal ataxia and left arm and leg dysmetria. The skull $X$-ray revealed calcification in the pineal region with a 6 millimeter displacement to the left. A combined Conray 60 ventriculogram and air encephalogram showed a large posterior third ventricle tumor and hydrocephalus (Fig. 7). Calcification could also be seen in the tumor. The patient was first shunted, then a sub-total excision of the tumor was done. The patient was subsequently radiated and is doing well one year later.

The biopsy specimen (No. 6562-74) showed an histologic appearance similar to case 1 (Fig. 5) with the same clear cells and lymphocytic component but without any plasmodial formation.

\section{DISCUSSION}

Intracranial dysgerminomas are usually found in the midline, in the pineal or para-pineal region. However, in 1961, Kageyama and Belsky, in reviewing 50 cases in the literature, recognized that fourteen of them and the two cases that they reported, had their origin in the optic chiasma or the infundibular region. The pineal body was free of involvement. The hypothalamic involvement when present seemed to be a direct extension from the suprasellar region. Cohen et al. (1974) reported one case of suprasellar germinoma.

In two of our patients, the primary site was the pineal or parapineal region. They presented clinically with signs of increased intracranial 
pressure. The second case presented with visual disturbance and diabetes insipidus: the suprasellar origin of the tumor was confirmed at autopsy.

One of our cases is of particular interest since on first admission the tumor was shown to occupy the pineal region and disappeared completely following radiation. On a second admission, the pineal region was free of tumor but a lesion was demonstrated in the fourth ventricle. Since there was no direct extension of the tumor through the vermis, one has to accept that it had metastasized through cerebrospinal fluid. Such a finding is rare (Cravioto, Dart, 1973; Dastur, Lalitha, 1972; Degirolami, Schmidek, 1973; Jellinger, 1973; Kageyama, 1971; Kageyama, Belsky, 1961; Katsura, Suzuki, Wada, 1965; Simson et al., 1968).

In the earlier literature, the suprasellar dysgerminomas were usually classified as ectopic pinealomas
(Kageyama, 1971; Russel, Rubinstein, 1971). The suprasellar or pineal dysgerminomas belong to a large group of tumors which originate from germ cells. Microscopically and ultrastructurally, intracranial dysgerminomas, pineal or suprasellar, have the same appearance as those from the gonads, mediastinum and retroperitoneum (Cravioto, Dart, 1973; Jellinger, 1973; Simson et al., 1968; Russell, Rubinstein, 1971; Marksberry et al., 1976).

If the pathogenesis of intracranial dysgerminomas is considered, their morphological and physiological characteristics are identical to those originating in other areas. They develop in the midline from germ cells (Jellinger, 1973). Germ cells have been found in the head of the embryo.

Of all intracranial neoplasms, the incidence of dysgerminomas varies from $0.39 \%$ to $1.73 \%$ (Katsura et al., 1959; Dastur, Lalitha, 1972). They

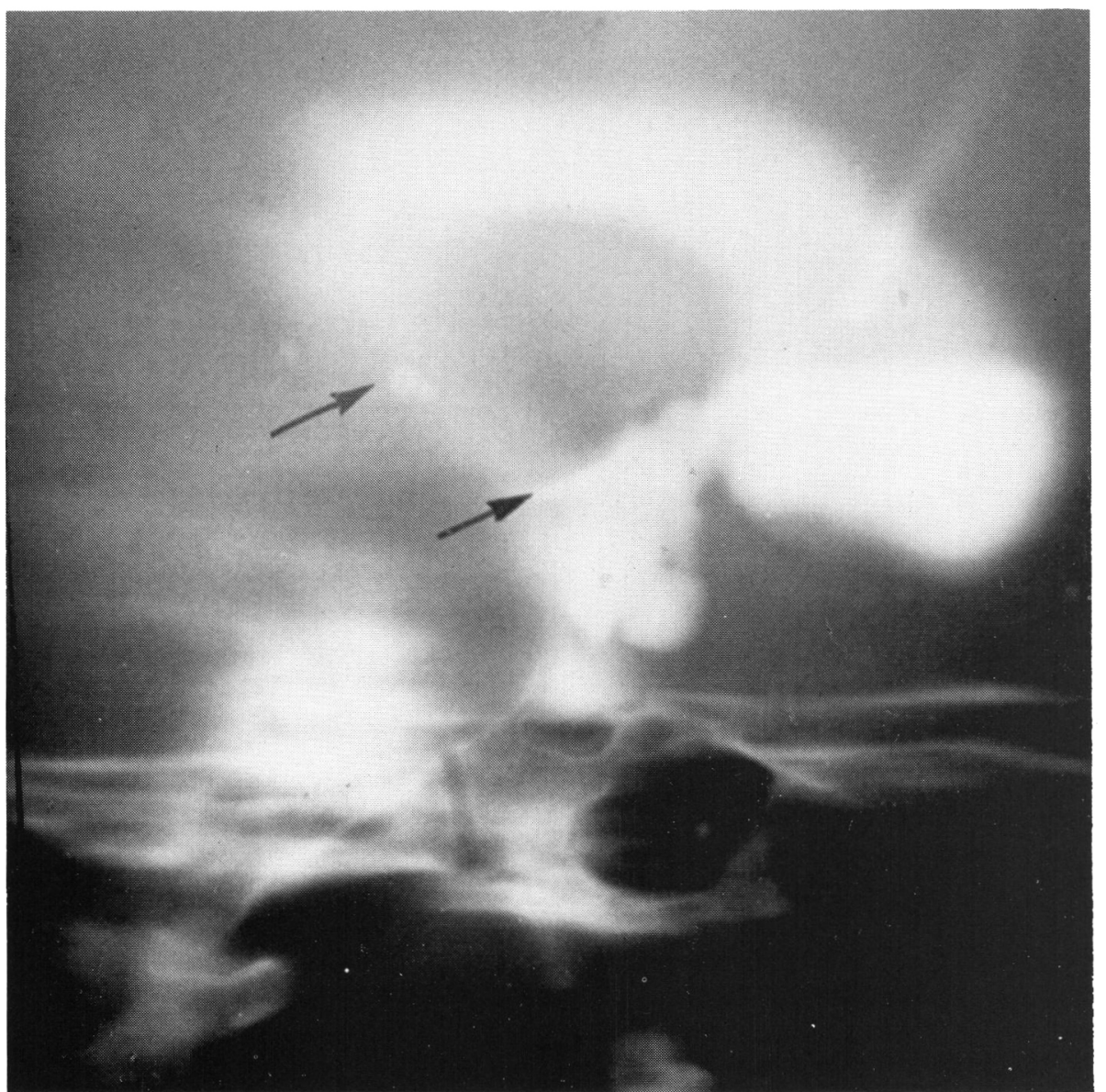

Figure 7-Case 3. Calcification is seen in the posterior part of the third ventricle (upper arrow) as well as the tumor (lower arrow). usually develop in patients who are under twenty years of age. Some papers report their occurrence equally in males and females. Others report a $75 \%$ occurrence in males. Two of our cases were males, and all were under twenty years of age.

\section{ACKNOWLEDGMENT}

We would like to thank Mrs. Armande LaBrecque of the Department of Neurological Sciences at l'Enfant-Jésus Hospital for her excellent assistance in preparing this paper.

\section{REFERENCES}

CABANNE, F., TOMMASI, $M$, and MICHIELS, R. (1965). Les Tumeurs de la Region Pineale. Annales d'Anatomie pathologique, Paris, 10: 41-60.

COHEN, D. N., STEINBERG, M. and BUCHWALD, R. (1974). Suprasellar Germinomas: Diagnostic Confusion with Optic Gliomas. Journal of Neurosurgery 4l: 490-493.

CRAVIOTO, H. and DART, D. (1973). The Ultrastructure of "Pinealoma". Journal of Neuropathology and Experimental Neurology, 32: 552-565.

DASTUR, D. K. and LALITHA, V. S. (1972). Pathological Analysis of Intracranial Space-Occupying Lesions in 1000 Cases including Children (Part IV). Journal of Neurological Sciences 15: 397-427.

DEGIROLAMI, U. and SCHMIDEK, $H$. (1973). Clinicopathological Study of 53 Tumors of the Pineal Region. Journal of Neurosurgery, 39: 455-462.

JELLINGER, K. (1973). Primary Intracranial Germa Cell Tumors. Acta neuropathologica, 23: 291-306.

KAGEYAMA, N. (1971). Ectopic Pinealoma in the Region of the Optic Chiasm. Journal of Neurosurgery 35: 755-759.

KAGEYAMA, N. and BELSKY, R. (1961). Ectopic Pinealoma in the Chiasma Region. Neurology 11: pp 318-327.

KATSURA. S., SUZUKI, J. and WADA, T. (1959). A Statistical Study of Brain Tumours in the Neurosurgical Clinics in Japan. Journal of Neurosurgery, 16: 570-580.

LAZAR, M. and KEMP, C. (1974). Direct Surgical Managements of Masses in the Region of the Vein of Galen. Surgical Neurology 2: 17-21.

RUSSELL, D. S. and RUBINSTEIN, L. J. (197I). Pathology of Tumours of the Nervous System. Ed. Arnold, 3e Edition, London, pp 208-214.

SIMSON. L. R., LAMPE, I. and ABELL, M. R. (1968). Suprasellar Germinomas. Cancer, 22: pp 533-544.

MARKSBERRY, W. R., BROOKS, W. H., MILSOW, L. and MORTARA, R. H. (1976). Ultrastructural Study of the Pineal Germinoma in Vivo and in Vitro. Cancer 37: pp 327-337. 